\title{
Analysis of the Role of Generic Benchmarking on Service Delivery: The perspective of Multinational Pharmaceutical Companies in Nairobi City County, Kenya
}

\author{
Betty Mukiri Murerwa*, Godfrey Muigai Kinyua \\ School of Business, Kenyatta University, Nairobi, Kenya \\ *Corresponding Authors: Betty Mukiri Murerwa, School of Business, Kenyatta University, Nairobi, \\ Kenya
}

\begin{abstract}
Improved service delivery in pharmaceutical industry is vital in saving the lives of children dying of malaria and other infectious diseases in Africa. This call for effective provision of medical services though the administration of pharmaceutical products. Hence, the study sought to investigate the effect of generic benchmarking on service delivery of the Multinational Pharmaceutical Companies in Nairobi City County, Kenya. The goal orientation Theory gave guidance to the study. The Descriptive research design was adopted for use. The study population for the research study was the management and employees from the multinational pharmaceutical companies based in Nairobi County and this made it easy for data collection since the majority have got their headquarters based within Nairobi. The instruments implemented in this research study was questionnaires which were developed and presented by the researcher to the study's participants. The census method of sampling was adopted for use in getting the sample to be included in the study. The collected data was then sorted out and descriptive and inferential analysis were run to analyze the quantitative data by use of the SPSS software. The analyzed data was then presented by use of graphs, tables and pie charts in the forms of frequencies, standard deviations and means. Findings indicated that generic benchmarking affected service delivery in multinational pharmaceutical firms to great extent. It was recommended that future scholars to carry out similar study but in different fields such as financial and agricultural sector to check whether the findings would concur.
\end{abstract}

Key words: Generic Benchmarking and Service Delivery.

\section{INTRODUCTION}

The pharmaceutical industry is crucial in constant production, development, and magrketing of medication to the potential clients who need to seek their services.It is indisputable for the huge importance of the pharmaceutical sector in the ever-changing global economy According to a report given by PROPARCO in 2012, there would be $200 \%$ of pharmaceutical firms in Africa alone come 2021. In 2014, the total revenue collection made in pharmaceutical industries within North America alone exceeded one trillion US dollars (WHO Report, 2015). The African drug market has been of importance in terms of service delivery and was considered to be the one to save lives in African countries in the next years to come (Ndomondo, Miot, Naidoo, Dodoo\&Kaale, 2017). With the absence of pharmaceutical industries, there would be more illnesses and high mortality rates recorded globally.

According to a report given out by a study done by Health Africa (2015), half of Africans could not get access to the essential drugs they require for their illnesses. Africa is also known to be having a high percentage representation of Acquires Immune Deficiency Syndrome (AIDS) and other outbreaks such as Cholera, Polio, measles, and tetanus (Torre \&Albercio, 2020). These illnesses have called for an increased number of drugs that need to be administered. This therefore necessitates an increase in the number of pharmaceutical companies in Africa. Kenyan Pharmaceutical industry has a high level of competition and was featured by wars in prices. Government policies dictate the price structure given out by the multinational pharmaceutical firms (Otieno, 2014). Therefore, to remain relevant in the industry by providing quality services, the firms then adopt strategies as tools for survival. This paper, therefore, sought to determine the generic strategies and service delivery in multinational pharmaceutical firms in Nairobi County. 
Ensuring accessibility in the drugs produced meets the minimum quality standard and securing the important functions of a well-established pharmaceutical system. Well delivered service qualifies if it meets and exceeds the expectations of the customer when it comes to quality, quantity, and cost. Service delivery in pharmaceutical firms in Kenya is one of the significant contributors to their success (Mailu, Ntale\&Ngui, 2018). Compliance with the regulations set by regulators such as the Pharmacy and Poisons Board is one of the crucial ways that has made the multinational pharmaceuticals offer appropriate service delivery to the consumers. Multinational corporations engage in very useful and defensive activities in developing countries although they receive very little credit. Compared to local firms, multinationals provide critical financial infrastructure and better resources for economic and social development (Peterson, 2013).

According to a survey conducted by KEMSA (2015), 307 pharmaceutical firms manufacture generic drugs intended for the local and export market. Despite this factor, the country continuous to heavily import drugs to cater for the needs of the public health sector. The pharmaceutical industry in Kenya was undergoing major changes which included shrinking margins, changes in demographics, emerging markets and rapid changes in technology. The proliferation of counterfeit and unregulated medical drugs is of the hindrance to the achievement of Kenyan Universal Health Care (Kenya Healthcare Federation \& Taskforce Healthcare, 2016).

Numerous studies have been done on performance in multinational pharmaceutical firms in Kenya: Jenifer and Allan (2017) performed a study on factors affecting manufacturing firms, with a particular interest in pharmaceutical firms based in Nairobi City County. Their study used profitability, market share, and sales volume as a measure of performance. Ouma, (2018), assessed the factors that are considered critical for success in pharmaceutical firms in Kenya. Some of these studies were done years ago and other outside the country, these gaps formed the aim of the current study which was to assess the effect of generic benchmarking strategy on service delivery of Multinational Pharmaceutical firms in Nairobi, City County, Kenya.

\section{LITERATURE REVIEW}

\subsection{Serviqual Model}

The model can also be referred to as the RATER model. It was developed and implemented in the mid-1980s by academic researchers Zeithaml, Parasuraman and Berry. Serviqual model illustrates the fact that the quality of service offered by a firm is the bridge between customers' expectations for the service offered and the perception of the service actual received (Ayele, 2012). As the model measures the attitude of perceived service opposed to the actual service offered, thus cannot clearly depict satisfaction. Customer gap is the main notable difference existing expectations of customers and their perceptions. Customer expectations is what the customer sees themselves getting out of a firm based on the available resources, influenced by cultural background, lifestyle, personality, advertising and experience with similar products. According to Newman (2001), in spite of the controversies concerning the validity and reliability of serviqual, its application can be found in healthcare. Therefore, this model was used to anchor service delivery as the dependent variable.

\subsection{Empirical Literature Review}

Another study conducted by Ouma (2014), on benchmarking practices and service delivery of the Kenya Revenue Authority. The study found out that KRA adopted strategic and process benchmarking as expressed in the reform and modernization Program and the corporate plan objectives. The findings of the study led the researcher to make the conclusion that benchmarking contributes considerably to the success of KRA's service delivery to Kenyan citizens both in revenue collection and verification of tax compliances.

A case study was done by Gershom (2013) on benchmarking strategies and service delivery of resorts and spa in Diani recorded a high correlation between benchmarking strategies and service delivery. The analysis from the multiple regression findings showed that benchmarking strategies had a positive and significant relationship with the service delivery of resorts and spa in Diani, Kenya. Recommendation that top priority should be given to these strategies was given. This study addressed the contextual gap by focusing on Pharmaceutical Firms in Nairobi City County, Kenya, thereby addressing the contextual gap. 
Furthermore, Sajabi (2012) conducted an exploration on benchmarking practices used adopted for use by commercial banks in Nairobi. The researcher of the survey made the conclusion that benchmarking had a tremendous influence on improving the operations of many firms in terms of service delivery. As per the researcher, benchmarking was seen to have the potential of continuously playing an important role in the success of the commercial banks. A future study to be done on the effects of benchmarking on the success of pharmaceuticals in Kenya.

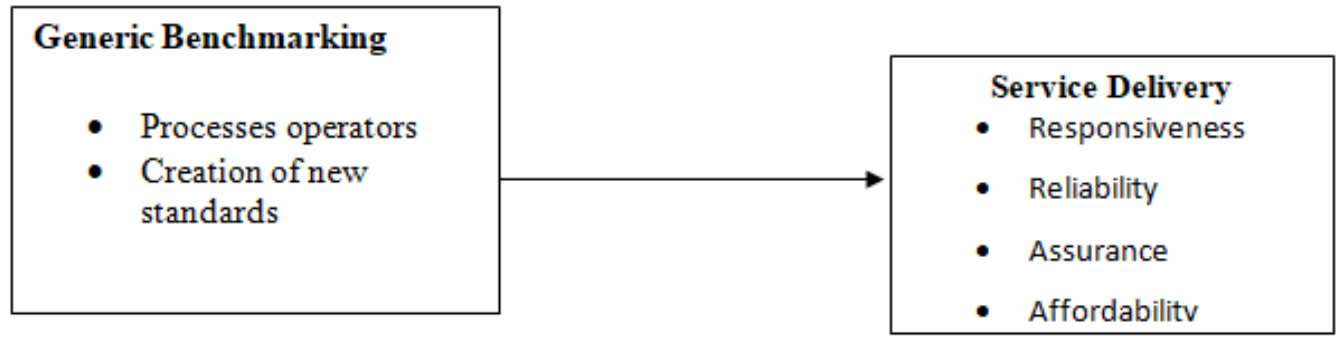

Independent Variables

Dependent Variable

Figure1.Conceptual Framework

Source: Researcher (2021)

Therefore, from the developed conceptual framework, the research objective for the study became;

To determine the effect of generic benchmarking on service delivery in Multinational Pharmaceutical Firms in Nairobi City County, Kenya.

\section{RESEARCH METHODOLOGY}

According to Creswell (2014), a research design is a framework that a researcher chooses to help in tackling the research problem at hand. For the study,descriptive research survey design was adopted. This method made it possible to collect data on generic benchmarking strategy and service delivery in multinational pharmaceutical firms in Nairobi City County, Kenya. Notably, the descriptive research design has been in previous research studies (Mbugua\&Kinyua, 2020; Gatuyu\&Kinyua, 2020; Kimencu\&Kinyua, 2020; Omollo, 2016). . Mugenda and Mugenda (2013), state that a study's population comprises of cases or elements that have similar characteristics of interest to the researcher. For this survey, the population was made up of the management employees from the multinational pharmaceutical companies based in Nairobi County.These firms included; GlaxoSmithKline (GSK) pharmaceuticals, Betta Healthcare International, Bayer East Africa, Roche pharmaceuticals, Sanofi, Novartis and Pfizer Labs Limited.

Table1.Target Population

\begin{tabular}{|l|l|l|}
\hline Strata Target & Population & Percentage \\
\hline Senior Management & 20 & $15.6 \%$ \\
\hline Middle Management & 30 & $23.4 \%$ \\
\hline Employees & 78 & $61 \%$ \\
\hline TOTAL & $\mathbf{1 2 8}$ & $\mathbf{1 0 0}$ \\
\hline
\end{tabular}

Source: Human resource department (2019)

The census survey method was adopted to gain insight from all the 128 employees in management level from the Multinational Pharmaceutical firms concerning service delivery. A census survey was deemed appropriate as the population of study was not too large hence capturing all the relevant data to enable comparison of the strategies in place by these firms.

With the help of structured questionnaires, primary data were collected for purpose of analysis. This instrument was preferred for its ability to reach a wider number of respondents easily and the fact that it is relatively cheap yet giving quality responses. Questionnaires are also free from bias, making it a better tool (Trochim, 2006). To ensure the instrument was valid, the researcher sought the advice from professionals in the area of the study, as well as the supervisor who guided gave appropriate guidance. Additionally, reliability was tested by conducting a pilot test prior to the actual data collection. The Chronbach alpha coefficients determined if the content of the instrument were reliable enough to give consistent results. Table 2 presents the Cronbach alpha results. 
Analysis of the Role of Generic Benchmarking on Service Delivery: The perspective of Multinational Pharmaceutical Companies in Nairobi City County, Kenya

Table2. Reliability Test

\begin{tabular}{|l|l|l|l|}
\hline Variable & Cronbach Alpha Index & Number of Items & Comment \\
\hline Generic Benchmarking & 0.791 & 4 & Reliable \\
\hline Service Delivery & 0.836 & 6 & Reliable \\
\hline Aggregate Score & $\mathbf{0 . 7 8 9}$ & $\mathbf{1 0}$ & Reliable \\
\hline
\end{tabular}

Source: Pilot Data (2020)

From the table above, generic benchmarking had a reliability of $(\alpha=0.791)$, while service delivery recorded a reliability coefficient of $(\alpha=0.789)$ and an aggregate coefficient of $(\alpha=0.789)$ all the variables of the study were reliable as they surpassed the 0.7 coefficient requirement provided by Gibson (2014) thus, they were reliable to be used in the study.

The collected data was then filtered out and edited to make it relevant. The edited data was then put in codes to ease the process of analysis. The Statistical Package for Social Sciences (SPSS) version 25 software was then used to conduct the analysis the descriptive and inferential statistics. Results were presented in forms of tables, graphs and pie charts with percentages, means and standard deviation. Inferential statistics analysis included correlation, multi-regression and ANOVA. The linear regression model is presented below:

$\mathbf{Y}=\boldsymbol{\beta}_{0}+\boldsymbol{\beta}_{1} \mathbf{X}_{1}+\varepsilon$ ...Model 1

Where;

$\mathbf{Y}=$ Service Delivery

$\mathbf{X}_{\mathbf{1}}=$ Generic Benchmarking

$\boldsymbol{\beta}_{0,}, \boldsymbol{\beta 1}$, = beta coefficients

$\boldsymbol{\varepsilon}=$ Error term

The simple linear regression was conducted for purpose of establishing the relationship between generic benchmarking and service delivery of Multinational pharmaceutical firms in Nairobi City County, Kenya. ANOVA test tested the significance of the model by indicating the probability of occurrence of $\mathrm{R}^{2}$. ANOVAs F-statistic measured the fitness of the estimated regression model at $95 \%$ confidence level where the p-value of 0.05 was used as the threshold for inferences. A corresponding beta coefficient was regarded statistically significant at $95 \%$ confidence level if it was below 0.05 .

\section{RESEARCH FINDINGS AND DISCUSSION}

128 questionnaires were administered to the respondents, 104 properly filled and returned. This gave an $81 \%$ response rate, which was sufficient for the researcher to proceed with analysis. This response rate was acceptable as agreed by Orodho (2014) which considers a response rate of above $70 \%$ sufficient enough to draw conclusions from.

\subsection{Descriptive Statistics}

The descriptive analysis results helped in making it easier to understand the distribution patterns of the data as well as indicating the level to which the respondents related with statements on external benchmarking and service delivery.

Table1. Descriptive Statistics for Generic Benchmarking

\begin{tabular}{|c|c|c|c|}
\hline Statement & $\sum_{\Sigma}^{\mathbb{E}}$ & 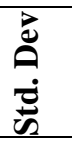 & j \\
\hline Generic benchmarking has a greater impact on the service strategies company. & 1.41 & 0.21 & 12 \\
\hline $\begin{array}{l}\text { Generic benchmarking leads to the acquisition of new culture that improves } \\
\text { service delivery. }\end{array}$ & 1.07 & 0.19 & 11 \\
\hline Generic benchmarking is crucial in the acquisition of service delivery skills. & 1.25 & 0.22 & 15 \\
\hline $\begin{array}{l}\text { Generic benchmarking makes it easy to identify the gaps in terms of reliability } \\
\text { and affordability. }\end{array}$ & 1.44 & 0.18 & 13 \\
\hline Aggregate Index & 1.29 & 0.20 & 13 \\
\hline
\end{tabular}

Source: Survey Data (2020) 
Analysis of the Role of Generic Benchmarking on Service Delivery: The perspective of Multinational Pharmaceutical Companies in Nairobi City County, Kenya

As per the results presented in table 1, the mean values for the generic benchmarking variable ranged between 1.07 as the lowest and 1.44 as the highest mean. For the standard deviation, the highest was 0.22 and the lowest standard deviation was 0.18 . The coefficient of variation range was between $11 \%$ and $15 \%$. Which showed that the responses given did not have much deviation. The aggregate mean for the variable was 1.29, standard deviation 0.20and CV 13\%. These results indicate that the mean presented could be used to make generalization of the general population as it was stable enough.

Table2. Descriptive statistics for service delivery

\begin{tabular}{|c|c|c|c|}
\hline Statement & 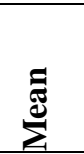 & 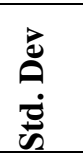 & 己 \\
\hline $\begin{array}{l}\text { Ease access of drugs by the consumers affect the service delivery of the multinational } \\
\text { pharmaceutical firms }\end{array}$ & 1.67 & 0.12 & 16 \\
\hline $\begin{array}{l}\text { Implementation of service delivery measuresis vital for the performance of } \\
\text { multinational pharmaceutical firms in Kenya }\end{array}$ & 1.33 & 0.54 & 14 \\
\hline $\begin{array}{l}\text { Efficiency of performance of multinational pharmaceutical firms is measured based on } \\
\text { modes of service delivery }\end{array}$ & 1.35 & 0.62 & 18 \\
\hline Adopting a follow-up survey is a better indicator of the nature of service provided & 1.38 & 0.47 & 22 \\
\hline $\begin{array}{l}\text { Service delivery in multinational pharmaceutical firms is a reflection on the levels of } \\
\text { consumers satisfaction }\end{array}$ & 1.58 & 0.31 & 21 \\
\hline Aggregate Index & 1.46 & 0.41 & 19 \\
\hline
\end{tabular}

Source: Survey Data (2020)

Presented in table 2 is the descriptive statistics for service delivery, as per the results, the aggregate mean, standard deviation and Coefficient of variation was $1.46,0.41$ and $19 \%$ respectively. The highest mean for the statements was 1.67 and the lowest was 1.33. As for the standard deviations, the highest and lowest value was 0.62 and 0.12 respectively. The range of the CV was between 14 and $22 \%$.The low variation in the coefficient of variations indicated that the responses did not vary a lot and the mean could be used to make generalization of the entire population of Multinational pharmaceutical firms in Nairobi City County, Kenya.

\subsection{Inferential Statistics}

The analysis of the linear regression was done with the independent variable generic benchmarking and dependent variable service delivery. Multi-regression analysis incorporated the ANOVA calculation together with the coefficient determination of $\left(\mathrm{R}^{2}\right)$ and finally the regression coefficients. Results of the multi-regression analysis are as shown below.

Table3. Model Summary

\begin{tabular}{|l|l|l|l|l|}
\hline \multicolumn{5}{|c|}{ Model Summary } \\
\hline Model & R & R Square & Adjusted R Square & Std. Error of the Estimate \\
\hline 1 & $.567^{\text {a }}$ & .320 & .299 & .61728 \\
\hline
\end{tabular}

Source: Survey Data (2020)

As per the table, the correlation coefficient $(\mathrm{R})$ was $0.567, \mathrm{R}^{2}$ was 0.320 which indicated that $32.1 \%$ of service delivery of the multinational firms in Nairobi City County, Kenya was influenced by generic benchmarking.

Table4. ANOVA Analysis

\begin{tabular}{|l|l|l|l|l|l|}
\hline Model 1 & Sum of Squares & DF & Mean of Squares & F & Sig. \\
\hline Regression & 15.511 & 8 & & & $.000^{\mathrm{b}}$ \\
\hline Residual & 34.776 & 60 & 5.470 & 14.368 & \\
\hline Total & 50.287 & 68 & .380 & & \\
\hline a.Dependent Variable: Service Delivery & \\
\hline
\end{tabular}

Source: Survey Data (2020)

Results presented in table 4 show there was a high level of significance, justified by a $p$ value of 0.000 , which is less than 0.05 , which is used to measure significance. 
Analysis of the Role of Generic Benchmarking on Service Delivery: The perspective of Multinational Pharmaceutical Companies in Nairobi City County, Kenya

Table5.Coefficients

\begin{tabular}{|c|c|c|c|c|c|}
\hline \multicolumn{6}{|c|}{ Coefficients } \\
\hline & Un-st: & ized Coefficients & Standardized Coefficients & $\mathbf{t}$ & Sig \\
\hline & Beta & Std. Error & Beta & & \\
\hline Constant & 1.313 & .445 & & 2.947 & .004 \\
\hline Generic Benchmarking & 0.09 & .142 & .167 & 2.423 & .008 \\
\hline
\end{tabular}

Source: Survey Data (2020)

Table 5 above provides the beta results for establishing the statistical model provided below:

Service Delivery $=1.313+0.142$ Generic Benchmarking Model 2

Results of the table show that generic benchmarking had a $\beta$ of 0.09 , p-value of 0.008 and $\alpha=0.05$, which show that it has a positive and statistically significant influence on service delivery of international pharmaceutical firms in Nairobi City County. Hence, when management of the firms improve generic benchmarking by one unit, it reflects by a significant improvement of service delivery by 0.09 unit in the positive direction.

These findings are in agreement by studies conducted by Mwayayi (2015), on benchmarking strategy for service delivery enhancement. The researcher found that generic benchmarking had a positive significant relationship with service delivery. Bogeta (2017), study findings revealed a relationship that was significant and positive amongst generic benchmarking and performance. These findings are parallel with the RATER model which describe different modes of service delivery and quality experienced by customers.

\section{CONCLUSION AND RECOMMENDATION}

The study's focus was to examine the effect generic benchmarking had on service delivery of multinational pharmaceutical firms in Nairobi City County. The correlation between generic benchmarking and service delivery was positive, therefore, it was concluded that generic benchmarking (process operators, creation of new standards) had a significant effect on service delivery. Additionally, generic benchmarking was found to influence service delivery of the firms in a positive and significant way.

Given the significance of generic benchmarking on service delivery, it was recommended that there should be an adoption of a follow-up survey where pharmaceutical firms ask customers to rate their service quality through an email survey was a better indicator of the nature of service provided, which will enable the pharmaceutical firms get informed about the strides made by other firms through which they will have improved service delivery.

\subsection{Areas for Further Research}

This survey was delimited to determining the external benchmarking strategy and service delivery in multinational pharmaceutical firms in Nairobi City County, future researchers should do similar studies in different fields such as financial sectors and Agricultural sectors to assess whether the results would be similar to those found in this study.

\section{REFERENCES}

[1] Ayele, A. (2012). Positioning Strategies Adopted by Five Star Hotels in Nairobi, Kenya. Unpublished MBA Project. Nairobi: University of Nairobi.

[2] Bogeta, C. (2017). Assessing the Role of Benchmarking on the Performance of Supermarkets a Case of Supermarkets in Kisii County.

[3] Kialyulo, M., \& Kinyua, G. M. An Empirical Analysis of the Relationship between Strategic Outsourcing and Performance of Kenya Commercial Bank in Kenya.

[4] King'oo, R. N., Kimencu, L., \& Kinyua, G. (2020). The Role of Networking Capability on Organization Performance: A Perspective of Private Universities in Kenya. Journal of Business and Economic Development, 5(3), 178-186.

[5] Kinyua, M. N. (2014). Strategies adopted by multinational pharmaceutical firms in Kenya to respond to competitive rivalry in the pharmaceutical industry (Doctoral dissertation). 
Analysis of the Role of Generic Benchmarking on Service Delivery: The perspective of Multinational Pharmaceutical Companies in Nairobi City County, Kenya

[6] Kung'u, S. M., Kahuthia, J., \& Kinyua, G. (2020). Analysis of the Effect of Strategic Direction on Performance of Motor Vehicle Assembly Firms in Nairobi City County, Kenya. International Journal of Managerial Studies and Research, 8(8), 2-94.

[7] Lwiki, T., Ojera, P. B., Mugenda, N. G., \& Wachira, V. K. (2013). The impact of inventory management practices on financial performance of sugar manufacturing firms in Kenya. International Journal of Business, Humanities and Technology, 3(5), 75-85.

[8] Mailu, R. N., Ntale, J. F., \&Ngui, T. K. (2018). Strategy implementation and organizational performance in the pharmaceutical industry in Kenya. International Academic Journal of Human Resource and Business Administration, 3(2), 33-47.

[9] Mwayayi, R. D. (2015). Benchmarking strategy for service delivery enhancement at Kenya ports authority (Doctoral dissertation, University of Nairobi).

[10] Ndomondo-Sigonda, M., Miot, J., Naidoo, S., Dodoo, A., \&Kaale, E. (2017). Medicines regulation in Africa: current state and opportunities. Pharmaceutical medicine, 31(6), 383-397.

[11] Ouma, A. M. (2018). Influence of value disciplines strategy on the management of efficiency levels in the pharmaceutical industry in Kenya (Doctoral dissertation, JKUAT).

[12] Ouma, A. M. (2018). Influence of value disciplines strategy on the management of efficiency levels in the pharmaceutical industry in Kenya (Doctoral dissertation, JKUAT).

[13] Ouma, J. (2014). Benchmarking Practices and Performance of Kenya Revenue Authority. MBA Project School of Business, University of Nairobi

[14] Peterson, R. A., \& Kim, Y. (2013). On the relationship between coefficient alpha and composite reliability. Journal of applied psychology, 98(1), 194.

[15] Sajabi, D. W. (2012). Benchmarking practices used by commercial banks in Nairobi (Doctoral dissertation).

[16] Tannoury, M., \&Attieh, Z. (2017). The influence of emerging markets on the pharmaceutical industry. Current therapeutic research, 86, 19-22.

\section{AUTHORS' BIOGRAPHY}

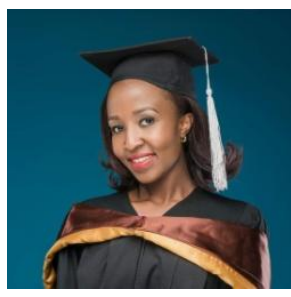

Betty MukiriMurerwa, is a logistics assistant in a pharmaceutical organization. She holds a Degree in Bachelor of Commerce in Purchasing and Business Logistics from Daystar University, Kenya. Currently pursuing a Degree in Master of Business Administration in Strategic Management from Kenyatta University, Kenya. Her key areas of interest in research is global supply chain management. She has experience in procurement and logistics operations within the healthcare industry in which has become well versed in the procurement and logistics processes. This includes practical experience in management of inventory and sourcing of Promotional and trade materials globally for the Pharmaceutical industry.

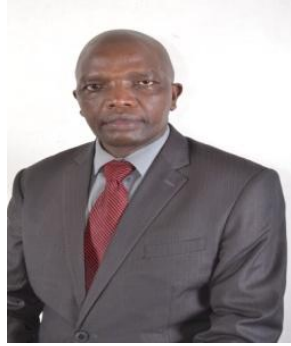

Dr. Godfrey M. Kinyua, is a Lecturer in the Department of Business Administration, School of Business of Kenyatta University. He holds a Doctor of Philosophy in Business Administration from Kenyatta University, Master of Business Administration from the University of Nairobi and Bachelor of Education from Egerton University. His key areas of interest in research includes knowledge management, competitive intelligence and green innovation.

Citation: Betty Mukiri Murerwa, Godfrey Muigai Kinyua. "Analysis of the Role of Generic Benchmarking on Service Delivery: The perspective of Multinational Pharmaceutical Companies in Nairobi City County, Kenya" International Journal of Managerial Studies and Research (IJMSR), vol 9, no. 6, 2021, pp. 32-38. doi: https://doi.org/10.20431/2349-0349.0906004.

Copyright: (0) 2021 Authors. This is an open-access article distributed under the terms of the Creative Commons Attribution License, which permits unrestricted use, distribution, and reproduction in any medium, provided the original author and source are credited. 